\title{
Results of Chronic Neck Pain Rehabilitation at Cotonou
}

\author{
H. Etienne Alagnide*, Wilfried Dahoueto, D. Didier Niama Natta, Herman Azanmasso, \\ Yves Anani, Djimingaye Natoyallah, G. Toussaint Kpadonou
}

University Clinic of Physical Medicine and Rehabilitation, National University Hospital Center (CNHU-HKM), Cotonou, Benin

Email: *ealagnide@yahoo.fr

How to cite this paper: Alagnide, H.E., Dahoueto, W., Niama Natta, D.D., Azanmasso, H., Anani, Y., Natoyallah, D. and Kpadonou, G.T. (2021) Results of Chronic Neck Pain Rehabilitation at Cotonou. Open Journal of Therapy and Rehabilitation, 9, 154-161.

https://doi.org/10.4236/ojtr.2021.94013

Received: August 23, 2021

Accepted: November 23, 2021

Published: November 26, 2021

Copyright $\odot 2021$ by author(s) and Scientific Research Publishing Inc. This work is licensed under the Creative Commons Attribution International License (CC BY 4.0).

http://creativecommons.org/licenses/by/4.0/

\begin{abstract}
Background: Neck pain is a real public health problem. Its treatment uses different techniques, such as functional rehabilitation, whose results are not widely popularized, from developing countries in Black Africa. Objective: To assess the result of rehabilitation of chronic common neck pain (CCNP) at the CNHU-HKM in Cotonou. Methods: Cross-sectional, retrospective, descriptive and analytical study. It was carried out from May to September 2020, based on the files of former patients followed in functional rehabilitation department at CNHU-HKM in Cotonou, from 2015 to 2019, for CCNP. The result of rehabilitation was assessed based on the progress, between the start and the end of the rehabilitation sessions, of pain intensity, mobility of the cervical spine, muscle strength and functional capacity of the patient. Anova and chi-square tests were used for the analysis of factors associated with the result of rehabilitation. Results: The sample consisted to 73 patients. They were predominantly female (58.90\%), with a mean age of $53.60 \pm 14.08$ years. The neck pain, at least of moderate intensity (97.26\%), was present since $12.54 \pm 8.54$ months, on average. Patients have done 10 to 20 functional rehabilitation sessions, the result of which was satisfactory in $67.12 \%$. This result was mainly associated with patient's age, sports practice and the seniority of pain progression. Discussion-Conclusion: Rehabilitation results in the management of CCNP are interesting. They prove the need to sensitize patients and prescribers on the importance of early treatment of CCNP.
\end{abstract}

\section{Keywords}

Chronic Neck Pain, Functional Rehabilitation, Results, Cotonou

\section{Introduction}

As low back pain, neck pain is a real public health problem throughout the world [1]-[6]. Indeed, it is a very common condition whose physical and psycho-social 
consequences are not negligible. Also, its direct and indirect costs are significant, particularly when the condition enters to chronic phase. This treatment uses various strategies including functional rehabilitation. The latter is available in the main hospital of Benin, since the beginning of that hospital. The team in this care sector has gradually grown and has continued to benefit from refresher courses since the 2000s. Certainly, from the review of the literature, several works have reported the benefits of rehabilitation. But the experience of developing countries has been poorly documented. What are the results of this rehabilitative care in our context, at CNHU-HKM in Cotonou?

\section{Method}

We conducted a retrospective, descriptive and analytical cross-sectional study, from May $1^{\text {st }}$ to September $30^{\text {th }}, 2020$, on patients fulfilling those conditions:

- To have been followed in functional rehabilitation department at CNHU-HKM in Cotonou, between 2015 and 2019 (5 years) for common chronic neck pain,

- To have had a medical file, found during the data collection period,

- To have benefited of functional rehabilitation sessions, with an assessment at the beginning and end of sessions.

So, patients seen after medical examination and who have not done rehabilitation sessions or decide to do them in an other center or who begin but have not finished rehabilitation sessions, where excluded. With those criteria, seventythree (73) patients were enrolled in the sample of the study.

The evaluation of the rehabilitation result took into account the evolution of four parameters between the start and the end of the rehabilitation. These are the intensity of pain, the cervical spine joint mobility, the neck muscles strength and the patient functional status. Regarding the intensity of neck pain, its evolution was said to be considerable or negligible depending on whether the ratio between the intensity scores at the end and the beginning of the sessions was less than or greater than $50 \%$. For the evolution of the mobility of cervical spine, muscle strength and functional state of the patient, it was said to unchanged, negligible or considerable depending on whether the deficiency of the variable remained unchanged, reduced compared to the initial assessment or has completely disappeared. The overall result of the rehabilitation was said to be satisfactory, little satisfactory or unsatisfactory depending on whether the patient had a considerable change in at least three, two, or less than two of the four parameters studied. Data collected was analyzed with the software Epi Info. Factors associated with rehabilitation result were investigated using Anova and Pearson chi-square tests. The significance level chosen was 0.05 .

\section{Results}

\subsection{Characteristics of the Sample}

\subsubsection{Socio-Demographic Characteristics}

Patients ranged from 19 to 88 years old, with a mean age of $53.60 \pm 14.08$ years. These were 43 women (58.90\%) and 30 men (41.10\%). Table 1 presents the oth- 
er socio-demographic characteristics of patients of our study.

\subsubsection{Clinical Features of Neck Pain}

Patients were feeling pain, since 3 to 38 months, before they were admitted to rehabilitation, with a mean of $12.54 \pm 8.54$ months. The median time was 9 months. Neck pain was at least moderate intensity with $97.26 \%$ of patients. Functional impairment, cervical joint limitations and muscles weakness were the most impaired deficiencies associated to patients' neck pain. Figure 1 and Figure 2 present distribution of patients according to the severity of their neck pain and other impairments associated with neck pain upon admission to rehabilitation.

Table 1. Distribution of patients of the sample, according to their socio-demographic characteristics.

\begin{tabular}{|c|c|c|c|}
\hline & & Number & Percentage (\%) \\
\hline \multirow{4}{*}{ Corpulence } & Thinness & 06 & 8.22 \\
\hline & Normal & 38 & 52.05 \\
\hline & Overweight & 19 & 26.03 \\
\hline & Obesity & 10 & 13.70 \\
\hline \multirow{4}{*}{ Marital status } & Married & 46 & 63.01 \\
\hline & Widowers & 10 & 13.70 \\
\hline & Single & 10 & 13.70 \\
\hline & Divorced & 07 & 9.59 \\
\hline \multirow{6}{*}{ Professional domain } & Administration & 18 & 24.66 \\
\hline & Trade & 17 & 23.29 \\
\hline & Health & 12 & 16.44 \\
\hline & Bank and finances & 11 & 15.07 \\
\hline & Teaching & 08 & 10.95 \\
\hline & Others & 07 & 9.59 \\
\hline \multirow{2}{*}{ Sport practice } & Yes & 40 & 54.79 \\
\hline & No & 33 & 45.21 \\
\hline
\end{tabular}

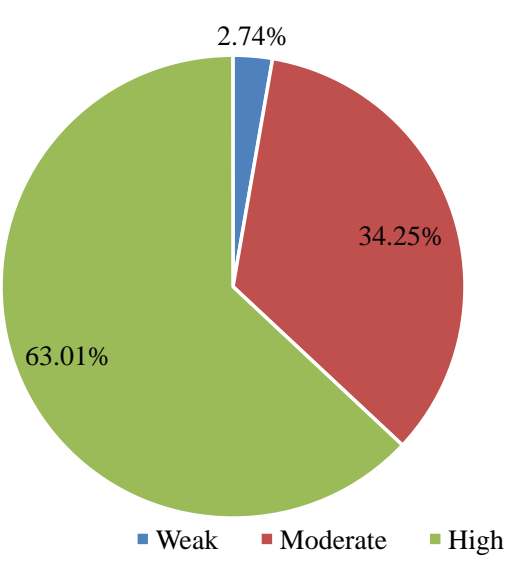

Figure 1. Distribution of patients according to their neck pain intensity. 


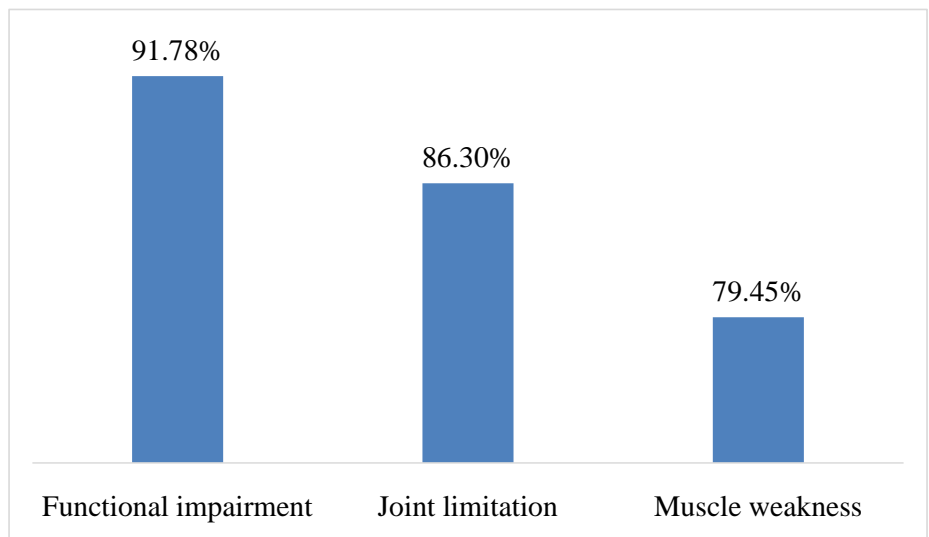

Figure 2. Proportions of impairments associated with neck pain in study patients.

\subsubsection{Rehabilitative Therapeutic Characteristics of Neck Pain}

Patients benefited from 10 to 20 functional rehabilitation sessions with an average of $15.82 \pm 4.56$ sessions.

\subsection{Rehabilitation Result}

The overall result of functional rehabilitation was satisfactory for 49 patients (67.12\%) and unsatisfactory for 24 patients (32.88\%). Parameters who were most improved were pain intensity, cervical joint mobility and patients functional status. Figure 3 shows the distribution of changes in the various parameters for assessing the overall result of functional rehabilitation.

\subsection{Factors Associated with the Overall Result of Functional Rehabilitation}

They are presented on Table 2 and Table 3. It was patient age, his marital status, the practice of sport and the duration that pain involves. So, younger was the patient, single or divorced he was, sport practice habit he has and shorter was the pain duration, patients were more satisfied.

\section{Discussion}

\subsection{Socio-Demographic Characteristics}

Patients of our sample were predominantly female, mostly married, in their 50s. Several authors have also reported results comparable to ours [7] [8] [9] [10] [11]. The very gradual onset of the disease could justify the patients' age in our sample. Also, women are more subject to various mechanical stresses on their spinal column during various activities done in profession and for daily life, hence their high proportion.

\subsection{Clinical Features}

Pain intensity was at least moderate in almost all of the patients of the study. This could be related to the chronicity of the condition and/or difficulties in ac- 
cessing health care in our context, forcing patients not to consider health problem early. This is noticeable in the period of pain progression which has been up to 38 months (over 3 years), with an average of one year. Park et al, meanwhile, reported longer delays in Korea, with an average of 30 months, two and a half years [7]. Pain was associated with other impairments such as functional limitation, muscle weakness and reduced joint mobility. Given the long period of development of neck pain, it is not surprising that such deficiencies set in secondarily.

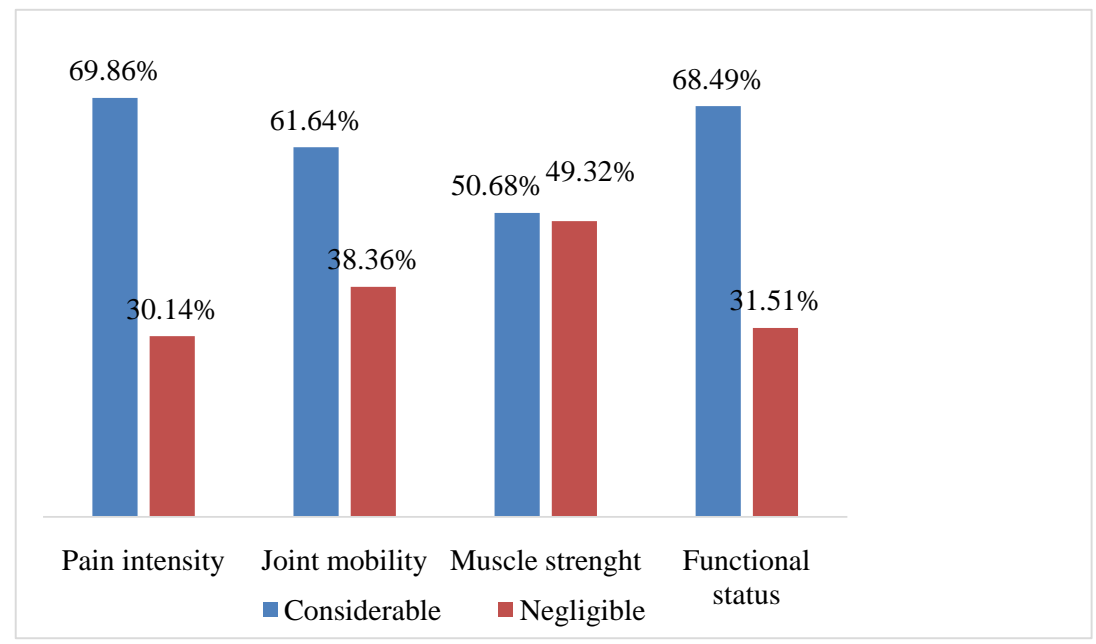

Figure 3. Distribution of changes in parameters for assessing the overall result of functional rehabilitation.

Table 2. Study of the link between the socio-demographic characteristics of patients and the overall result of functional rehabilitation of their neck pain.

\begin{tabular}{|c|c|c|c|c|}
\hline & & \multicolumn{2}{|c|}{ Overall result of rehabilitation } & \multirow{2}{*}{-Statistical tests } \\
\hline & & Satisfactory & Unsatisfactory & \\
\hline Age & Mean \pm SD & $46.08 \pm 9.59$ & $68.95 \pm 7.90$ & $\mathrm{~F}=102.27$ \\
\hline \multirow{2}{*}{ Gender } & Masculin & 19 & 11 & \multirow{2}{*}{$\begin{array}{c}\mathrm{X} 2=0.33 \\
\mathrm{p}=0.56\end{array}$} \\
\hline & Féminin & 30 & 13 & \\
\hline \multirow{4}{*}{ Marital status } & Single & 09 & 01 & \multirow{4}{*}{$\begin{aligned} X 2 & =13.65 \\
p & =0.00\end{aligned}$} \\
\hline & Married & 32 & 14 & \\
\hline & Divorced & 06 & 01 & \\
\hline & Widowers & 02 & 08 & \\
\hline \multirow{2}{*}{ Activity domain } & Public & 32 & 13 & \multirow{2}{*}{$\begin{array}{c}\mathrm{X} 2=0.58 \\
\mathrm{p}=0.61\end{array}$} \\
\hline & Private & 17 & 11 & \\
\hline \multirow{4}{*}{ Corpulence } & Thinness & 05 & 01 & \multirow{4}{*}{$\begin{array}{c}\mathrm{X} 2=0.98 \\
\mathrm{p}=0.80\end{array}$} \\
\hline & Normal & 25 & 13 & \\
\hline & Overweight & 13 & 06 & \\
\hline & Obesity & 06 & 04 & \\
\hline \multirow{2}{*}{ Sport practice } & Yes & 31 & 09 & \multirow{2}{*}{$\begin{array}{c}\mathrm{X} 2=4.31 \\
\mathrm{p}=\mathbf{0 . 0 3}\end{array}$} \\
\hline & No & 18 & 15 & \\
\hline
\end{tabular}


Table 3. Study of the link between clinical and rehabilitation characteristics of patients and the overall result of functional rehabilitation of their neck pain.

\begin{tabular}{|c|c|c|c|}
\hline & \multicolumn{2}{|c|}{ Overall result of rehabilitation } & \multirow{2}{*}{ Statistical tests } \\
\hline & Satisfactory & Unsatisfactory & \\
\hline \multicolumn{4}{|c|}{ Time to pain progression } \\
\hline Mean \pm SD & $9.97 \pm 7.2$ & $17.79 \pm 9.0$ & $\begin{array}{c}F=15.42 \\
p=0.00\end{array}$ \\
\hline \multicolumn{4}{|c|}{ Joint limitation } \\
\hline Yes & 41 & 22 & $\mathrm{X} 2=0.87$ \\
\hline No & 08 & 02 & $\mathrm{p}=0.35$ \\
\hline \multicolumn{4}{|c|}{ Muscle weakness } \\
\hline Yes & 38 & 19 & $\mathrm{X} 2=0.02$ \\
\hline No & 11 & 05 & $\mathrm{p}=0.87$ \\
\hline \multicolumn{4}{|c|}{ Functional status impaired } \\
\hline Yes & 45 & 22 & $\mathrm{X} 2=0.00$ \\
\hline No & 04 & 02 & $\mathrm{p}=0.98$ \\
\hline \multicolumn{4}{|c|}{ Number of rehabilitation session } \\
\hline 20 sessions & 23 & 14 & \multirow{3}{*}{$\begin{array}{c}\mathrm{X} 2=0.83 \\
\mathrm{p}=0.65\end{array}$} \\
\hline 15 sessions & 08 & 03 & \\
\hline 10 sessions & 18 & 07 & \\
\hline
\end{tabular}

\subsection{Outcome of Functional Rehabilitation and Associated Factors}

The result of functional rehabilitation was satisfactory in two out of three patients in our series. This indicates the interest of functional rehabilitation, in the management of neck pain. For that, various strategies are used. In fact, apart from the classic techniques of physiotherapy (thermotherapy, electrotherapy), are usualy used for the management of neck pain exercises of cervico-scapulo-thoracic strengthening, scapulo-thoracic endurance, cervico-scapulo-thoracic stabilization, cervico-scapulo-thoracic stabilization, eye-neck coordination, proprioception and combined strengthening and stretching exercises in the cervico-scapulothoracic region. Authors have reported that patients have beneficial effects of these techniques, in short, medium and long term [12] [13]. Age was very significantly associated with this outcome of functional rehabilitation. This could be related to the severity of the lesions over time, but certainly also because of the greater ability of young patients to participate in rehabilitation sessions. These two hypotheses seem to be confirmed by data in Table 3. In fact, the delay in the progression of pain $(p=0.00)$ and the practice of physical activity $(p=0.03)$ were also associated with the result of rehabilitation. But on the contrary, as the number of rehabilitation sessions, the other clinical deficiencies noted in chronic neck pain patients do not seem to determine the outcome of the rehabilitation treatment.

About limitation of the study, we can say that a comparative study must be 
better, to show specially what about the contribution of functional rehabilitation in these patients. But that ask about the usual ethical problem for these types of studies. Also, a more consistent sample size would be more attractive. The problems with archiving files in our context explained the smaller size used.

\section{Conclusion}

The impairments presented in cases of common chronic neck pain, in our context, are varied. They generally experience a satisfactory development, with functional rehabilitation sessions. This result is particularly marked in young people and patients with whom treatment was started earlier. These findings are parameters of conviction to emphasize the sensitization of patients and prescribers of rehabilitation care to send patients with neck pain as soon as possible to rehabilitation sessions.

\section{Conflicts of Interest}

The authors declare no conflicts of interest regarding the publication of this paper.

\section{References}

[1] Safiri, S., Kolahi, A.A., Hoy, D., Buchbinder, R., Mansournia, M.A., Betampadi, D., et al. (2020) Global, Regional and National Burden of Neck Pain in the General Population, 1990-2017: Systematic Analysis of the Global Burden of Disease Study 2017. BMJ, 2020, 369-391. https://doi.org/10.1136/bmj.m791

[2] Hoy, D., March, L., Woolf, A., Blyth, F., Brooks, P., Smith, E., et al. (2014) The Global Burden of Neck Pain: Estimates from the Global Burden of Disease 2010 Study. Annals of the Rheumatic Diseases, 73, 1309-1315. https://doi.org/10.1136/annrheumdis-2013-204431

[3] Haldeman, S., Carroll, L. and Cassidy, J.D. (2010) Findings from the Bone and Joint Decade 2000 to 2010 Task Force on Neck Pain and Its Associated Disorders. Journal of Occupational and Environmental Medicine, 52, 424-427. https://doi.org/10.1097/JOM.0b013e3181d44f3b

[4] Fejer, R., Kivik, K.O. and Hartvigsen, J. (2006) The Prevalence of Neck Pain in the World Population: A Systematic Critical Review of the Literature. European Spine Journal, 15, 834-848. https://doi.org/10.1007/s00586-004-0864-4

[5] Childs, J.D., Cledland, J.A., Elliott, J.M., Teyhen, D.S., Wainner, R.S., Whitman, J.M., et al. (2008) Neck Pain: Clinical Practice Guidelines Linked to the International Classification of Functioning, Disability and Health from the Orthopaedic Section of the American Physical Therapy Association. Journal of Orthopaedic \& Sports Physical Therapy 38, A1-A34. https://doi.org/10.2519/jospt.2008.0303

[6] Hoy, D.G., Protani, M. and Buchbinder, R. (2010) The Epidemiology of Neck Pain. Best Practice Research Clinical Rheumatology, 24, 783-792. https://doi.org/10.1016/j.berh.2011.01.019

[7] Park, S.J., Lee, R., Yoon, D.M., Yoon, K.B., Kim, K. and Kim, S.H. (2016) Factors Associated with Increased Risk for Pain Catastrophizing in Patients with Chronic Neck Pain: A Retrospective Cross-Sectional Study. Medicine, 95, e4698. https://doi.org/10.1097/MD.0000000000004698 
[8] Elbinoune, I., Amine, B., Shyen, S., Gueddari, S., Abouqal, R. and Hajjaj-Hassouni, N. (2016) Chronic Neck Pain and Anxiety-Depression: Prevalence and Associated Risk Factors. The Pan African Medical Journal, 24, 89-94.

https://doi.org/10.11604/pamj.2016.24.89.8831

[9] Cresswell, C., Galantino, M.L. and Myezwa, H. (2020) The Prevalence of Fear Avoidance and Pain Catostrophising amongst Patients with Chronic Neck Pain. South African Journal of Physiotherapy, 76, 1-6. https://doi.org/10.4102/sajp.v76i1.1326

[10] Good, A.P., Freburger, J. and Carey, T. (2010) Prevalence, Practice Patterns and Evidence for Chronic Neck Pain. Arthritis Care \& Research, 62, 1594-1601.

https://doi.org/10.1002/acr.20270

[11] Carroll, L.J., Hogg-Johnson, S., Cote, P., van der Velde, G., Holm, L.W., Carragee, E.J., et al. (2008) Course and Prognostic Factors for Neck Pain in Workers: Results of the Bone and Joint Decade 2000-2010 Task Force on Neck Pain and Its Associated Disorders. European Spine Journal, 17, 93-100.

https://doi.org/10.1007/s00586-008-0629-6

[12] Bertozzi, L., Gardenghi, I., Turoni, F., Villafane, J.H., Capra, F., Guccione, A.A. and Pillastrini, P. (2013) Effect of Therapeutic Exercise on Pain and Disability in the Management of Chronic Nonspecific Neck Pain: Systematic Review and Meta-Analysis of Randomized Trials. Physical Therapy, 93, 1026-1036.

https://doi.org/10.2522/ptj.20120412

[13] Gross, A.R., Paquin, J.P., Dupont, G., Blanchette, S., Lalonde, P., Cristie, T., et al. (2016) Exercises for Mechanical Neck Disorders: A Cochrane Review Update. Manual Therapy, 24, 25-45. https://doi.org/10.1016/j.math.2016.04.005 